\title{
Nasal ventilation in acute exacerbations of chronic obstructive pulmonary disease: effect of ventilator mode on arterial blood gas tensions
}

\author{
D J Meecham Jones, E A Paul, C Grahame-Clarke, J A Wedzicha
}

\begin{abstract}
Background - There are no controlled trials of the use of different modes of nasal intermittent positive pressure ventilation (NIPPV) in patients with exacerbations of chronic obstructive pulmonary disease (COPD). This study describes the effect on blood gas tensions of four different modes of nasal ventilation.
\end{abstract}

Methods - Twelve patients with acute exacerbations of COPD were studied (mean (SD) $\mathrm{FEV}_{1}$ 0.59 (0.13) $1, \mathrm{PaO}_{2}$ (air) 5.10 $(1 \cdot 12) \mathrm{kPa}, \mathrm{PaCO}_{2} 9 \cdot 28$ (1.97) $\mathrm{kPa}, \mathrm{pH} 7 \cdot 32$ $(0 \cdot 03))$. Each patient underwent four onehour periods of nasal ventilation in randomised order: (a) inspiratory pressure support $18 \mathrm{~cm} \mathrm{H}_{2} \mathrm{O}$; (b) pressure support $18 \mathrm{~cm} \mathrm{H} \mathrm{H}_{2} \mathrm{O}$ + positive end expiratory pressure (PEEP) $6 \mathrm{~cm} \mathrm{H} \mathrm{H}_{2} \mathrm{O}$ (IPAP + EPAP); (c) continuous positive airway pressure (CPAP) $8 \mathrm{~cm} \mathrm{H} \mathrm{H}_{2}$; and (d) volume cycled NIPPV. Arterial blood samples were obtained before each period of ventilation and at one hour.

Results - Pressure support, CPAP, and volume cycled NIPPV all produced significant improvements in $\mathbf{P a O}_{2}$; there was no difference between these three modes. The change in $\mathbf{P a O}_{2}$ with IPAP + EPAP did not reach statistical significance. None of the modes produced significant changes in mean $\mathrm{PaCO}_{2}$; patients with higher baseline levels tended to show a rise in $\mathrm{PaCO}_{2}$ whereas those with lower baseline levels tended to show a fall.

Conclusions - Although $\mathrm{PaO}_{2}$ improved in all patients there are differences in efficacy between the modes, while the changes in $\mathrm{PaCO}_{2}$ were variable. The addition of EPAP conferred no advantage in terms of blood gas tensions.

(Thorax 1994;49:1222-1224)

Table 1 Physiological data on admission

\begin{tabular}{|c|c|c|c|c|c|c|}
\hline $\begin{array}{l}\text { Patient } \\
\text { no. }\end{array}$ & $\begin{array}{l}\text { Age } \\
\text { (years) }\end{array}$ & $F E V_{l}(l)$ & $F V C(l)$ & $p H$ & $\begin{array}{l}\mathrm{PaO}_{2} \text { (air) } \\
(\mathrm{kPa})\end{array}$ & $\begin{array}{l}\mathrm{PaCO}_{2} \text { (air) } \\
(\mathrm{kPa})\end{array}$ \\
\hline 1 & 72 & 0.39 & 1.44 & $7 \cdot 36$ & $5 \cdot 15$ & $7 \cdot 77$ \\
\hline 2 & 62 & 0.86 & 1.61 & $7 \cdot 32$ & $4 \cdot 41$ & 8.69 \\
\hline 3 & 72 & 0.73 & 1.48 & $7 \cdot 35$ & $7 \cdot 12$ & $7 \cdot 26$ \\
\hline 4 & 68 & 0.43 & $1 \cdot 17$ & $7 \cdot 29$ & 3.94 & $13 \cdot 12$ \\
\hline 5 & 76 & 0.64 & $1 \cdot 76$ & $7 \cdot 30$ & $6 \cdot 89$ & $9 \cdot 11$ \\
\hline 6 & 49 & 0.48 & 1.01 & $7 \cdot 34$ & $5 \cdot 86$ & $8 \cdot 14$ \\
\hline 7 & 70 & 0.56 & 1.61 & $7 \cdot 38$ & $5 \cdot 24$ & $7 \cdot 02$ \\
\hline 8 & 67 & 0.51 & $1 \cdot 20$ & $7 \cdot 27$ & $4 \cdot 18$ & $13 \cdot 17$ \\
\hline 9 & 74 & 0.61 & $1 \cdot 11$ & $7 \cdot 32$ & 3.59 & $10 \cdot 78$ \\
\hline 10 & 70 & 0.73 & $2 \cdot 23$ & $7 \cdot 32$ & $5 \cdot 13$ & 8.05 \\
\hline 11 & 62 & 0.63 & $1 \cdot 26$ & $7 \cdot 29$ & 3.78 & $9 \cdot 31$ \\
\hline 12 & 62 & 0.56 & 1.43 & $7 \cdot 32$ & 5.94 & $9 \cdot 00$ \\
\hline \multicolumn{2}{|c|}{ Mean (SD) } & $0.59(0.13)$ & $1.44(0.34)$ & $7.32(0.03)$ & $5 \cdot 10(1 \cdot 12)$ & $9.28(1.97)$ \\
\hline
\end{tabular}

Acute hypercapnic respiratory failure due to chronic obstructive pulmonary disease (COPD) is associated with a high mortality rate. ${ }^{1}$ Nasal intermittent positive pressure ventilation (NIPPV) has been used in acute exacerbations of COPD with benefits including improvement in blood gases and reduced mortality compared with conventional therapy. ${ }^{2-5}$

We have shown no difference in efficacy between pressure and volume cycled nasal ventilator systems in patients with stable chronic respiratory failure, ${ }^{6}$ but there have been no studies comparing different ventilator systems in acute on chronic respiratory failure. We have investigated the effectiveness of two different systems of nasal ventilation and the effect of adding positive end expiratory pressure in patients with acute exacerbations of COPD.

\section{EQUIPMENT}

Two different nasal ventilator systems were used in this study, with ventilation through the Respironics nasal mask: (a) the BiPAP ventilatory support system (Respironics Inc, Murrysville, Pennsylvania, USA) is a pressure cycled ventilator adjusted to provide independent levels of inspiratory and expiratory positive airway pressures (IPAP and EPAP respectively), pressure support ventilation (IPAP), or CPAP; and (b) the BromptonPAC nasal ventilator (PneuPAC UK, Luton, UK) is a time and volume cycled system which functions in assist/control mode.

Spirometry was measured using a hand-held spirometer (Micro Medical Ltd, Rochester, Kent, UK). Arterial blood gases were measured with a CIBA Corning 278 blood gas system (Corning Medical, Medfield, Massachusetts, USA).

PATIENTS

Twelve patients (11 men, one woman) of median (range) age 69 (49-76) years were studied. Physiological data on admission are shown in table 1. All were judged to have acute exacerbations of COPD on clinical grounds, without focal consolidation on chest radiography, and showed deterioration in spirometry and arterial blood gases. Seven patients had used NIPPV during previous admissions and two patients were established on domiciliary NIPPV. All patients entered the study within 16 hours of admission after a period of initial assessment and therapy during which controlled oxygen therapy $(2 \mathrm{l} / \mathrm{min})$ and other 
Table 2 Mean changes $(k P a)$ in arterial blood gases $+95 \%$ confidence intervals for each ventilator mode studied

\begin{tabular}{lllll}
\hline & $\mathrm{PaO}_{2}$ & $95 \% \mathrm{CI}$ & $\mathrm{PaCO}_{2}$ & $95 \% \mathrm{CI}$ \\
\hline Pressure support & +2.50 & 1.06 to 3.95 & -0.29 & -0.59 to +0.01 \\
IPAP+ EPAP & +0.82 & -0.78 to +2.23 & -0.24 & -1.02 to +0.54 \\
CPAP & +1.35 & 0.10 to 2.79 & +0.25 & -0.18 to +0.68 \\
BromptonPAC & +2.34 & 1.34 to 3.38 & +0.04 & -0.51 to +0.60 \\
\hline
\end{tabular}

IPAP, EPAP = inspiratory and expiratory positive airway pressures; $\mathrm{CPAP}=$ continuous positive airway pressure. appropriate treatments were instituted. Oxygen therapy was continued for the duration of the study. Four patients were already established on intravenous doxapram at the start of the study, which was continued unchanged. All patients were treated with antibiotics, corticosteroids, and nebulised bronchodilators.

\section{STUDY DESIGN}

Baseline arterial blood gases were obtained from a radial artery catheter with patients breathing room air and oxygen. Each patient subsequently underwent four periods of nasal ventilation for one hour in randomised order: (a) pressure support $18 \mathrm{~cm} \mathrm{H}_{2} \mathrm{O}$; (b) pressure support $18 \mathrm{~cm} \mathrm{H}_{2} \mathrm{O}$ plus positive end expiratory pressure (PEEP) $6 \mathrm{~cm} \mathrm{H} \mathrm{H}_{2} \mathrm{O}$ (IPAP + EPAP); (c) continuous positive airway pressure (CPAP) $8 \mathrm{~cm} \mathrm{H}_{2} \mathrm{O}$; and (d) volume cycled NIPPV (BromptonPAC). Modes (a), (b), and (c) were performed with the BiPAP nasal ventilator ( $S$ setting), and in mode (d) the BromptonPAC ventilator was used. The EPAP settings were selected to correspond to the levels of intrinsic PEEP noted in similar patients in previous studies. ${ }^{7}$ All periods of ventilation were accomplished with the patient in a semirecumbent position and were supervised to ensure patient-ventilator synchrony and effect- ive triggering of ventilation. Arterial blood gas tensions were obtained immediately before each period of ventilation and at one hour. Owing to the poor clinical condition of these patients it was not technically possible to obtain data by more invasive methods. A minimum of one hour elapsed between different periods of ventilation, during which time blood gas tissues returned to a stable baseline. At the end of the study all patients were established on the mode of ventilation found to be most effective.

The study protocol was approved by the ethics committee of the Royal Brompton Hospital and informed consent was obtained from all subjects.

\section{STATISTICAL METHODS}

Data were analysed using the BMDP repeated measures of variance programme (BMDP Statistical Software, Los Angeles, California, USA).

\section{Results}

Pressure support $18 \mathrm{~cm} \mathrm{H}_{2} \mathrm{O}$, CPAP $8 \mathrm{~cm}$ $\mathrm{H}_{2} \mathrm{O}$, and volume cycled NIPPV (BromptonPAC) all produced significant improvements in $\mathrm{PaO}_{2}$ (table 2). Repeated measures analysis of variance showed no difference between these three modes. The change in $\mathrm{PaO}_{2}$ with IPAP + EPAP did not reach statistical significance and three patients experienced great difficulty in tolerating this mode. The order of study periods did not affect outcome.

None of the ventilator modes produced significant improvements in group mean $\mathrm{PaCO}_{2}$. However, the change in $\mathrm{PaCO}_{2}$ varied with the starting $\mathrm{PaCO}_{2}$. The changes in $\mathrm{PaCO}_{2}$ for each
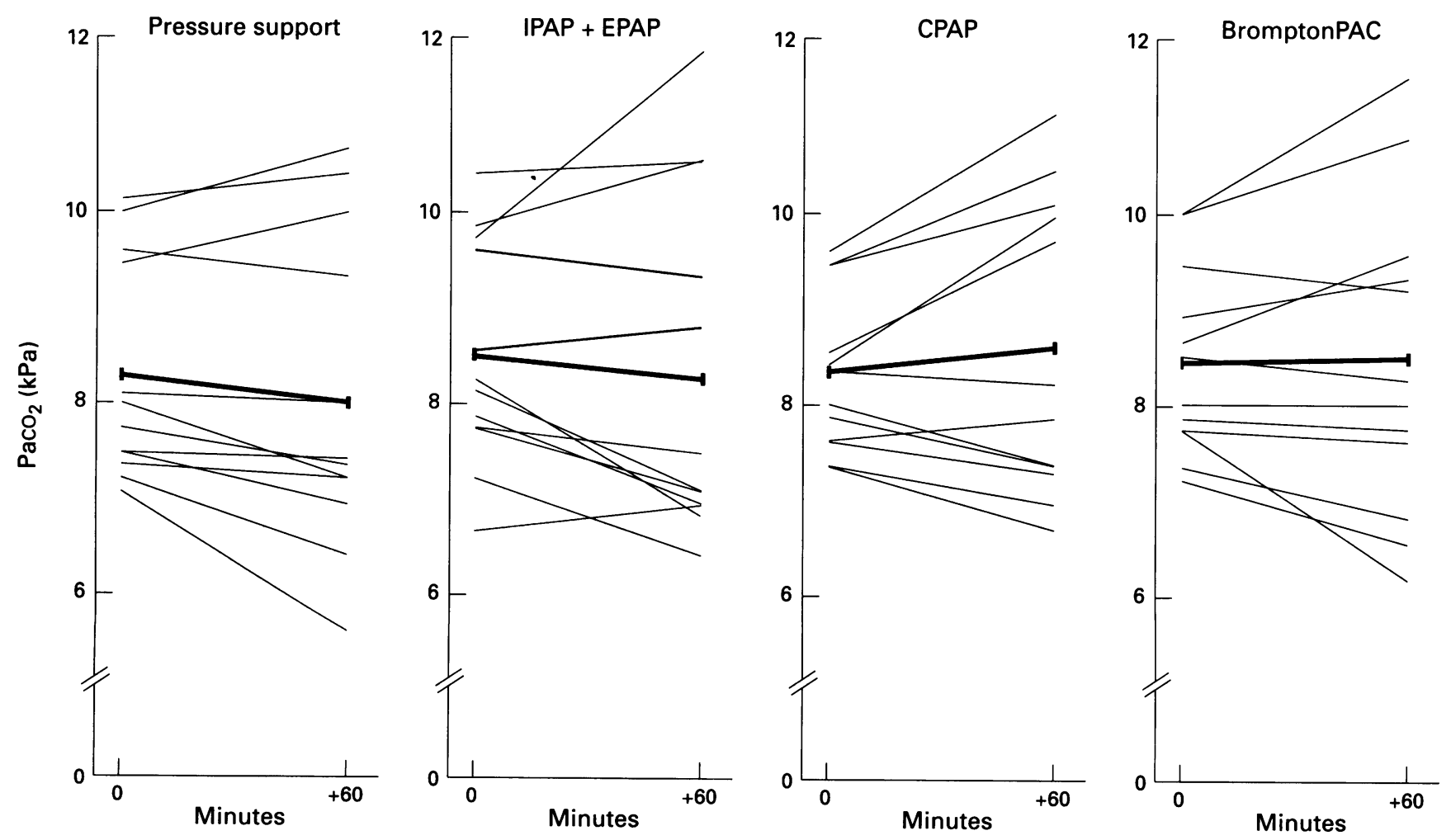

Individual $\left(\longrightarrow\right.$ ) and mean $\left(\longrightarrow\right.$ changes in $\mathrm{PaCO}_{2}$ for all patients $(n=12)$ achieved using each ventilator mode. 
ventilator mode are shown in the figure. When patients were divided into two groups above or below the median baseline $\mathrm{PaCO}_{2}$, and this was incorporated into the analysis of variance, it was found that patients with higher initial $\mathrm{PaCO}_{2}$ levels tended to rise further, while those with lower starting levels tended to fall with treatment. This interaction was significant with a probability value of $p<0.02$. For individual patients this response was consistent for each mode of ventilation; all of the four patients on doxapram infusions at the start of the study showed this pattern of response. No patient required formal mechanical ventilation. The 10 patients who were not on domiciliary ventilation used NIPPV for a median of six days (range 2-13). Mean $\mathrm{PaO}_{2}$ at discharge was 6.90 $(1.01) \mathrm{kPa}, \mathrm{PaCO}_{2} 7.53(0.81) \mathrm{kPa}$, median hospital stay 11 days (range 5-22). Five patients died during further acute exacerbations within six months of the study.

\section{Discussion}

This is the first study to compare the effect of different modes of nasal ventilation in patients with acute exacerbations of COPD. In this group of patients pressure cycled NIPPV, volume cycled NIPPV, and CPAP can bring about significant improvements in oxygenation, although the effect on $\mathrm{PaCO}_{2}$ is more variable. The addition of positive end expiratory pressure in the form of EPAP was poorly tolerated and produced no additional benefit.

$\mathrm{PaO}_{2}$ rose consistently with the addition of nasal ventilation whereas, although $\mathrm{PaCO}_{2}$ tended to fall in patients with lower starting arterial carbon dioxide tensions, in those with the highest initial levels of $\mathrm{PaCO}_{2}$ there was a further rise. A recent report of CPAP in patients with acute COPD showed a similar pattern of response. ${ }^{8}$ Positive end expiratory pressure causes a rise in functional residual capacity ${ }^{10}$ and consequent increase in airway calibre, preventing small airway closure and improving ventilation-perfusion relationships within the lungs. However, studies in normal subjects and in patients with acute respiratory failure have demonstrated that minute ventilation may fall with the application of CPAP ${ }^{11-13}$ due mainly to a reduced respiratory rate without changes in inspiratory flow rate.

In this study the most severely hypercapnic patients - most of whom required doxapram infusions to maintain or augment respiratory drive - showed a rise in $\mathrm{PaCO}_{2}$ with the addition of nasal ventilation. NIPPV increases minute ventilation, mainly through an enhanced tidal volume. During acute exacerbations of COPD airway resistance is high and compliance of the ventilatory system is low. In severely affected patients the ventilators used to deliver NIPPV may not be capable of generating sufficiently high pressures to increase minute ventilation enough to bring about a fall in $\mathrm{PaCO}_{2}$, although there may be other important effects on ventilation-perfusion matching and breathing pattern. The increase in $\mathrm{PaO}_{2}$ with nasal ventilation further compromised respiratory drive and the patients' active contribution to ventilation, imposing a greater degree of the workload on to the ventilator.

Leakage from around the nasal mask and mouth is common with NIPPV, particularly in acutely ill patients unfamiliar with the technique. During the study several patients experienced great difficulty in maintaining an adequate seal at the mouth, particularly when using the IPAP + EPAP mode. These patients were unable to adjust to the constant flow through the nasal mask and developed persistent leakage. We believe that this is a major factor accounting for the relative inefficiency of this particular mode of ventilation.

This study confirms that nasal ventilation is effective in improving arterial oxygen tensions. Although $\mathrm{PaCO}_{2}$ may be controlled in most patients, in those with severe hypercapnia and impaired respiratory drive $\mathrm{PaCO}_{2}$ may rise further with the initiation of NIPPV.

Nasal ventilation may be of particular use in those patients not considered suitable for tracheal intubation. It is important that this technique is used as an adjunct to maximal conventional therapy, and not as a substitute for intubation and formal mechanical ventilation if required on clinical grounds.

D J Meecham Jones is the British Lung Foundation Robert Luff Fellow.

1 Jeffrey AA, Warren PM, Flenley DC. Acute hypercapnic respiratory failure in patients with chronic obstructive lun disease: risk factors and use of guidelines for management. Thorax 1992;47:34-40.

2 Brochard L, Isabey D, Piquet J, Amaro P, Mancebo J, Messadi A, et al. Reversal of acute exacerbations of chronic obstructive lung disease by inspiratory assistance with a obstructive lung disease by inspiratory assistanc

3 Bott J, Carroll M, Conway JH, Keilty SEJ, Ward EM, Brown AM, et al. Randomised controlled trial of nasa ventilation in acute ventilatory failure due to chronic obstructive airways disease. Lancet 1993;341:1555-7.

4 Benhamou D, Girault C, Faure C, Portier F, Muir JF. Nasal mask ventilation in acute respiratory failure. Chest 1992; 102:912-7.

5 Chevrolet JC, Jolliet P, Abajo B, Toussi A, Louis M. Nasal positive pressure ventilation in patients with acute respiratory failure. Chest 1991;100:775-82.

6 Meecham Jones DJ, Wedzicha JA. Comparison of pressure and volume preset nasal ventilator systems in stable chronic respiratory failure. Eur Respir f 1993;6:1060-4.

7 Fleury B, Murciano D, Talamo C, Aubier M, Pariente R, Milic-Emili J. Work of breathing in patients with chronic obstructive pulmonary disease in acute respiratory failure. Am Rev Respir Dis 1985;131:822-7.

8 Miro AM, Shivaram U, Hertig I. Continuous positive airway pressure in COPD patients in acute hypercapnic respiratory failure. Chest 1993;103:266-8.

9 Schlobohm RM, Falltrick RT, Quan SF, Katz JA. Lung volumes, mechanics and oxygenation during spontaneous positive pressure ventilation: the advantage of CPAP over positive pressure ventilation: the advan

10 Downs JB, Klein EF, Modell JH. The effect of incremental PEEP on $\mathrm{PaO}_{2}$ in patients with respiratory failure. Anesth $\mathrm{PEEP}$ on $\mathrm{PaO}_{2}$ in patient
Analg $1973 ; 52: 210-5$.

11 Petrof BJ, Legare M, Goldberg P, Milic-Emili J, Gottfried SB. Continuous positive airway pressure reduces work of breathing and dyspnea during weaning from mechanical ventilation in severe chronic obstructive pulmonary disease. Am Rev Respir Dis 1990;141:281-9.

12 Katz JA, Marks JD. Inspiratory work with and without continuous positive airway pressure in patients with acute respiratory failure. Anesthesiology 1985;63:598-607.

13 Kesten S, Rebuck AS. Ventilatory effects of nasal continuous positive airway pressure. Eur Respir $\mathcal{f}$ 1990;3:498-501. 